\title{
A High Efficiency Maximum Power Point Tracker for Photovoltaic Arrays
}

\author{
Khalid Khleel Mohamed \\ Amina Edrees Kanaan \\ Electrical Engineering - Mosul University, Iraq
}

\begin{abstract}
The photovoltaic (PV) generator exhibits non- linear characteristics and its maximum power point varies with solar insolation and temperature, thus this work deals with the design and implementation of a real time maximum power point tracker(MPPT)for photovoltaic system aiming to improve energy conversion efficiency. A MPPT algorithm is developed using PV array voltage and current information's and the incremental conductance of the PV array, it's implemented by single chip 80C51 microcontroller to control the duty cycle of a boost converter with pulse width modulation (PWM). The practical and Simulation results shows the validity of the designed circuit to improve the tracking efficiencies to get the maximum power point.
\end{abstract}

Key words: solar panel, Maximum Power point tracker (MPPT), microcontroller.

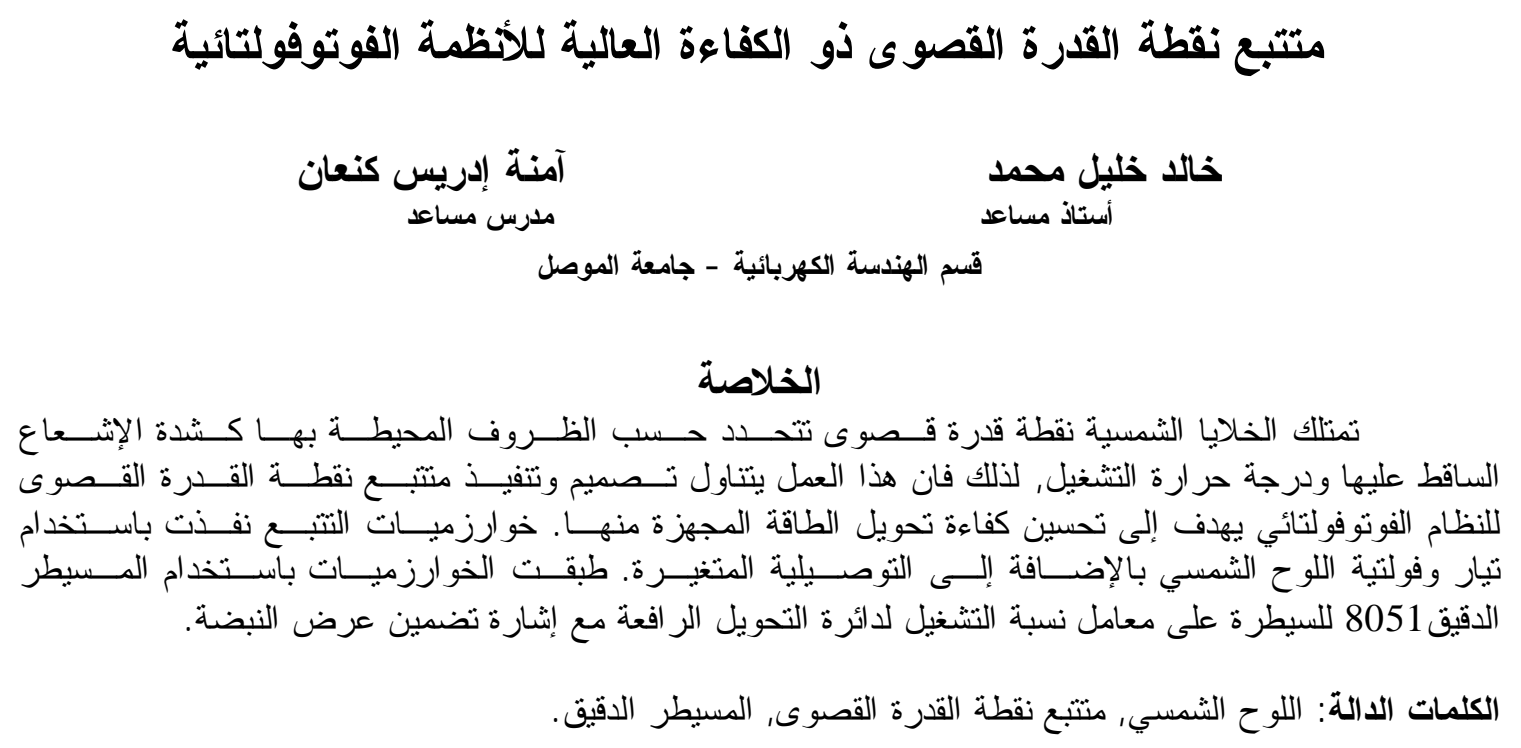

Received 20 Oct. 2008

Accepted 26 Feb. 2009 


\section{Al-Rafidain Engineering $\quad$ Vol.17 $\quad$ No.6 $\quad$ Dec. 2009}

\section{Introduction}

The rapid trend of industrialization of nations and increased interest in environmental issues recently led us to explore the use of renewable forms such as solar energy. Photovoltaic (PV) generation is gaining increased importance as a renewable source due to [1] [2] advantages such as the absence of fuel cost, little maintenance and no noise and wear due to the absence of moving parts, etc. In particular, energy conversion from solar cell arrays (SCAs) received considerable attention in the last two decades. The PV generator exhibits a nonlinear $\mathrm{i}-\mathrm{v}$ characteristic, and its maximum power (MP) point varies with the solar insolation and temperature. At a particular solar insolation, there is a unique operating point of the PV generator at which its power output is maximum. Therefore, for maximum utilization efficiency, it is necessary to match the PV generator to the load such that the equilibrium operating point coincides with the MPP of the PV source. However, since the MP point varies with insolation and seasons, it is difficult to maintain MP operation at all solar insolations. In this work a maximum power point tracking circuit is designed, the research can be classified into two parts: the first one is the tracking circuit, which is simulated using (MATLAB-Simulink) software. The solar panel is also simulated to be connected to the total system because it is not offer in the basic block of matlab. The Boost converter is simulated using (MATLAB-SimulinkIP.S.B) software, two algorithms are used to realize control and tracking process, the first one is the Perturbation and Observation algorithm and the second is the Incremental Conductance algorithm. The total simulated models are connected together to simulate the total photovoltaic system model.

In the second part, the tracking circuit is designed and implemented practically, the boost converter is designed following the procedure used in the simulated model, Where the control circuit is designed using a microcontroller chip, the microcontroller is programmed with the same algorithms used in the first part. Then the converter circuit is connected to the control circuit to implement the total system with the solar panel and the charging battery.

\section{Characteristics of solar arrays:}

Solar array characteristics profounding influence the overall system, which includes the converter and control scheme; therefore it will be briefly reviewed here. A solar cell is anon linear device and can be represented as a current source model as shown in figure (1)[3]:

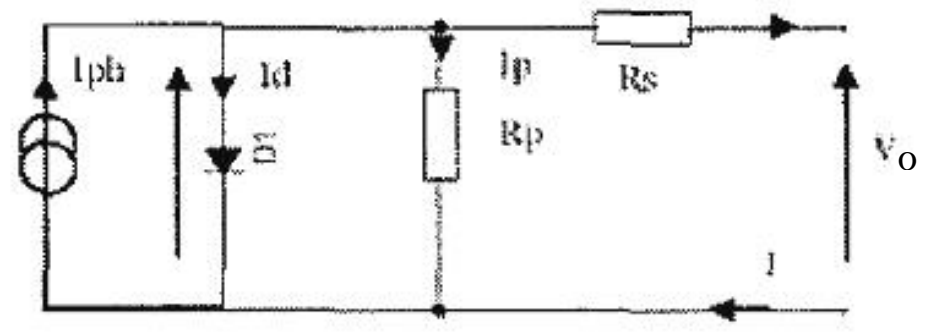

Figure (1): Simplified equivalent circuit of a solar cell.

The various parameters of the solar cell are modeled as follows: the current source generates photo current $\left(\boldsymbol{l}_{p h}\right)$, which is directly proportional to the solar irradiance. The two resistors $(\mathrm{Rp})$ and $(\mathrm{Rs})$ represent the losses incurred in the cell. The series resistor symbolies the voltage loss in the path due to the cell's external contacts primarily caused by the ohmic losses in the surface of the solar cell. The parallel shunt resistor (Rp) denotes the losses due to leakage current in the solar cell.

The traditional I-V characteristics of a solar cell, when neglecting the internal shunt resistance, are given by the following equation [4]: 
Mohamed : A High Efficiency Maximum Power Point Tracker for Photovoltaic ...

$$
I_{o}=I_{p h}-I_{s a t}\left\{\exp \left[\frac{q}{A K T}\left(V_{o}+I_{o} \cdot R_{s}\right)\right]-1\right\}
$$

Where (Iph) is the light generated current, (Isat) is the reverse saturated current, $\mathrm{q}$ is the electronic charge. A is the $\mathrm{p}-\mathrm{n}$ junction ideality factor (a dimensionless factor), $\mathrm{K}$ is the Boltzmann constant, $\mathrm{T}$ is the temperature in degree Kelvin and (Rs) is the series resistance of the cell.

When using equation (1) to simulate the solar cell parameter (neglecting the internal resistances) it can be shown that the solar cell has non-linear output characteristics. These output characteristics are shown in figures(2) and (3):

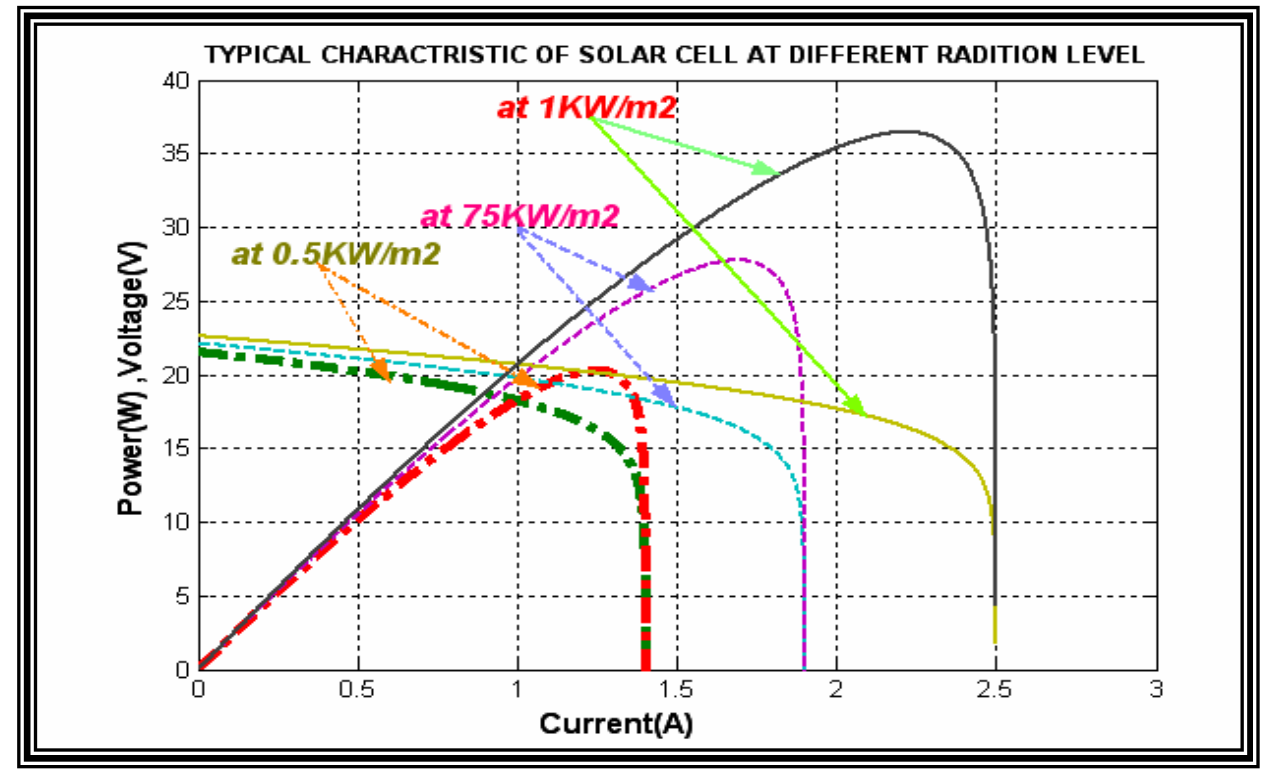

Figure (2): output I-V characteristics of a typical solar cell under different Radiations.

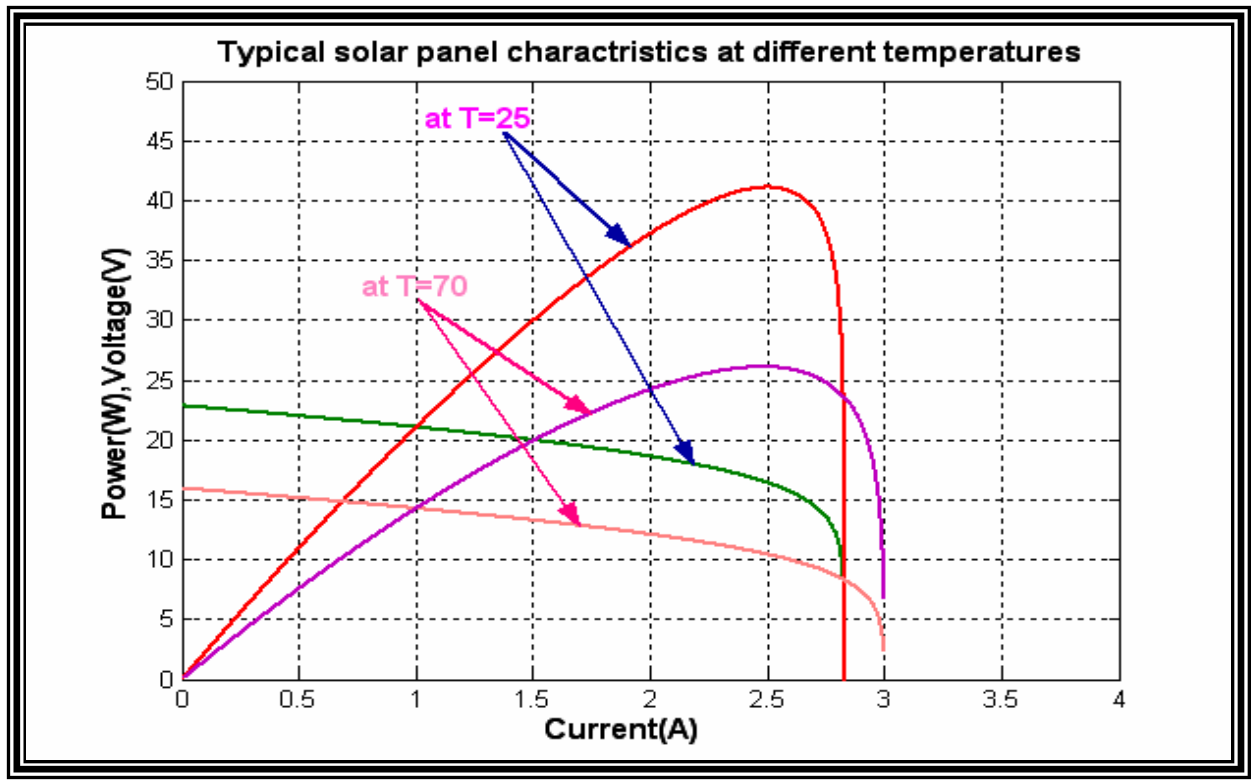

Fig. (3): output I-V characteristics of a typical solar cell under different temp.. 


\section{$\begin{array}{llll}\text { Al-Rafidain Engineering } & \text { Vol.17 } & \text { No.6 } & \text { Dec. } 2009\end{array}$}

\section{MPPT Control Approach}

As the power supplied by the solar array depends on the insolation, temperature and array voltage, an important consideration in the design of efficient solar array systems is to track the maximum power point correctly. The purpose of the MPPT is to move the array operating voltage close to the MPP under changing atmospheric conditions.

Many methods for tracking maximum power point had been proposed. Two algorithms often used to achieve the MPPT which are: the perturbation and observation (P\&O) method; and the incremental conductance (IncCond) method [5][6].

1. Perturbation and observation method

The perturbation and observation method has been widely used because of its simple feedback structure and fewer measured parameters. The peak power tracker operates by periodically incrementing or decrementing the solar array voltage. If a given perturbation leads to an increase (decrease) in array power, the subsequent perturbation is made in the same (opposite) direction. In this manner, the peak power tracker continuously hunts or seeks the peak power conditions.

\section{Incremental conductance method}

The solar array terminal voltage can be adjusted relatively to the MPP voltage by measuring the incremental and instantaneous array conductance (dI/dV and $\mathrm{I} / \mathrm{V}$ respectively). Although the incremental conductance method offers good performance under rapidly changing atmospheric conditions, but four sensor devices require more conversion time which result in a large amount of power loss.

In order to achieve maximum power point tracking two different control variables can be used[6][7].

\section{Voltage- feedback Control}

The solar array terminal voltage is used as the control variable for the system. The system keeps the array operation close to its maximum power point by regulating the array's voltage and matches the voltage of the array to a desired voltage. However, this has the following drawbacks:

(1) The effects of the insolation and temperature of the solar array are neglected.

(2) It cannot be widely applied to battery energy storage systems.

Therefore, this control is only suitable for use under constant insolation conditions, such as a satellite system, because it cannot automatically track the maximum power point of the array when variations in insolation and temperature occur.

\section{Power- feedback Control}

Maximum power control is achieved by forcing the derivative $(\mathrm{dP} / \mathrm{dV})$ to be equal to zero under power feedback control. A general approach to power feedback control is to measure and maximize the power at the load terminal. This method has the advantage of unnecessarily knowing the solar array characteristics. However, this method maximizes power to the load and not power from the solar array. Although a converter with MPPT offers high efficiency over a wide rang operating points, but for a bad converter, the full power may not be delivered to the load due to power loss. Therefore, the design of a high performance converter is very important issue [8]. 


\section{Simulation Result}

Matlab simulation software and its facilities are used to model a storage solar system with MPPT (in Boost mode) tracker as shown in fig.4 (a)

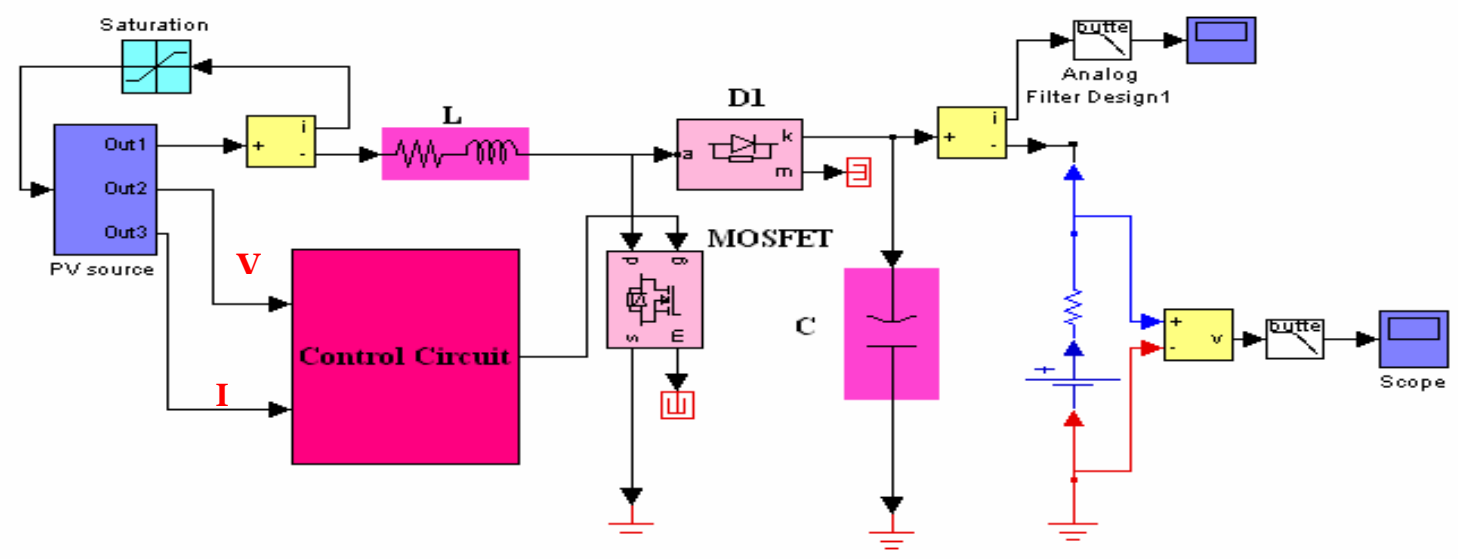

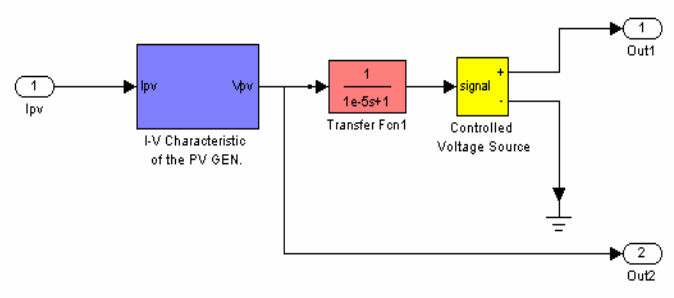

(b)

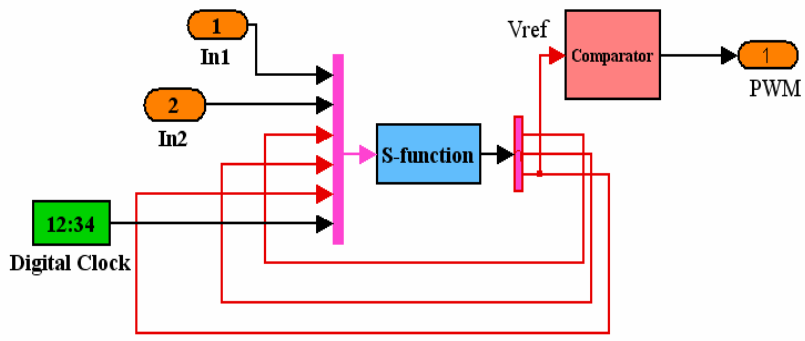

(c)

Figure (4): Simulation of a storage PV system with MPPT (in boost mode): (a) circuit diagram; (b) detail of "PV source" block; and (c) detail of "MPPT" block.

For the solar cell equivalent circuit, we have created a block called "PV source" as shown in fig.4(b) which simulates the nonlinear I-V characteristics of one solar panel, employing the cell short circuit current (Isc) as a measure of insolation level.

Also a delay function is introduced to limit the fast current response of the "controlled voltage source" and to improve the convergence of solution.

For the MPPT equivalent circuit, A block called "MPPT" as shown in fig.4(c), is used this block acts as a controller to execute the control algorithm (P\&O and IncCond) and calculates the firing commands for the pulse-width-modulation (PWM) block, the (MPPT)block is simulated using the simulink facilities(User defined system/S-function) which is execute the tracking algorithm and translates it to simulink block to added to be the total system.

Fig.5 shows computed voltage, current, and power characteristics of the "PV source" output block, and fig. 6 shows the charging current, when using P\&O and IncCond algorithm respectively. 

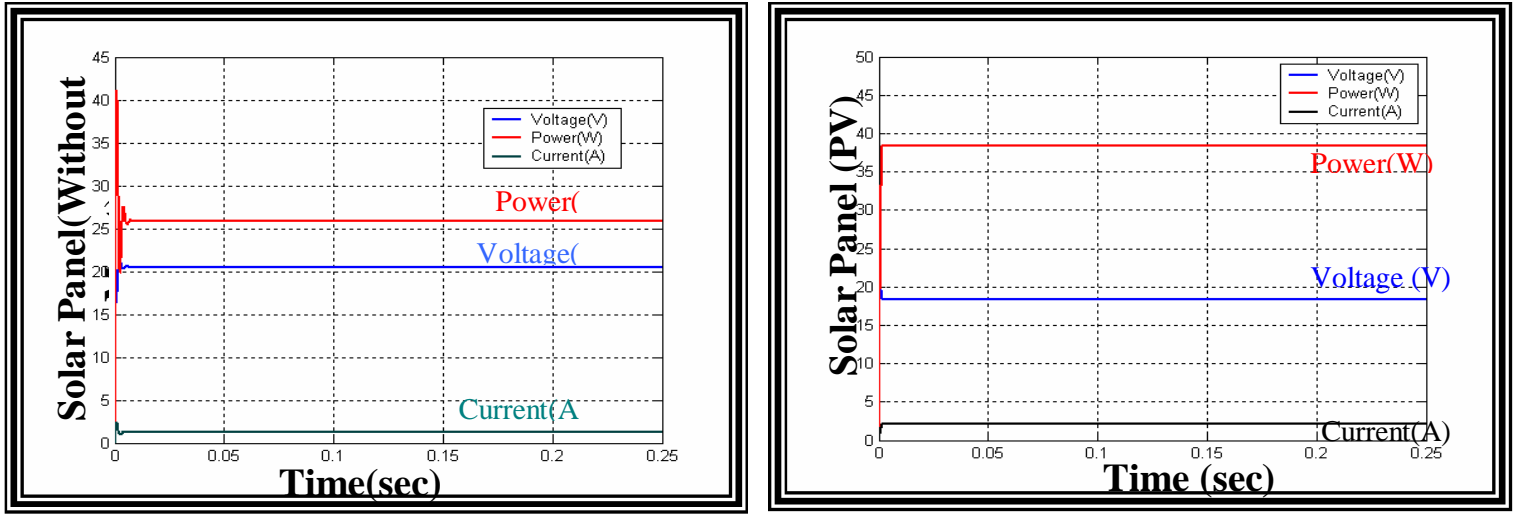

(a): without MPPT algorithm.

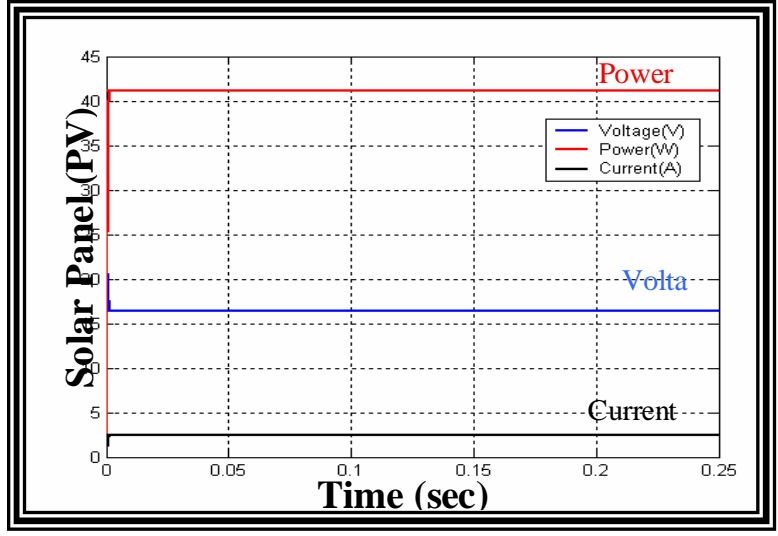

(c): with Incremental conductance algorithm.

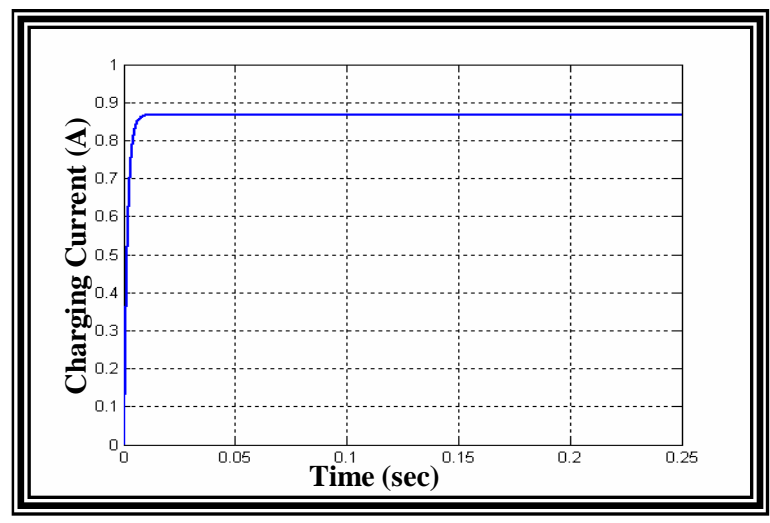

(a): charging current without MPPT.

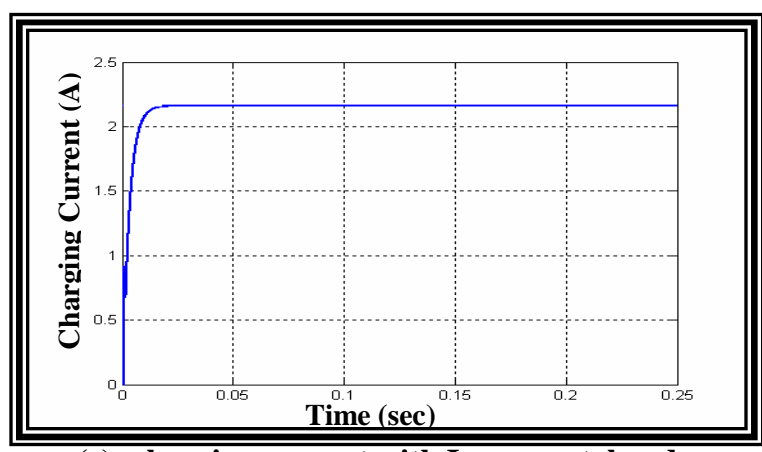

(c): charging current with Incremental and conductance algorithm.
Figure (5): Computed (using figure (4)) voltage, current, and power characteristics of the PV source. a)without MPPT algorithm. b) with P\&O algorithm and c) with IncCond algorithm.

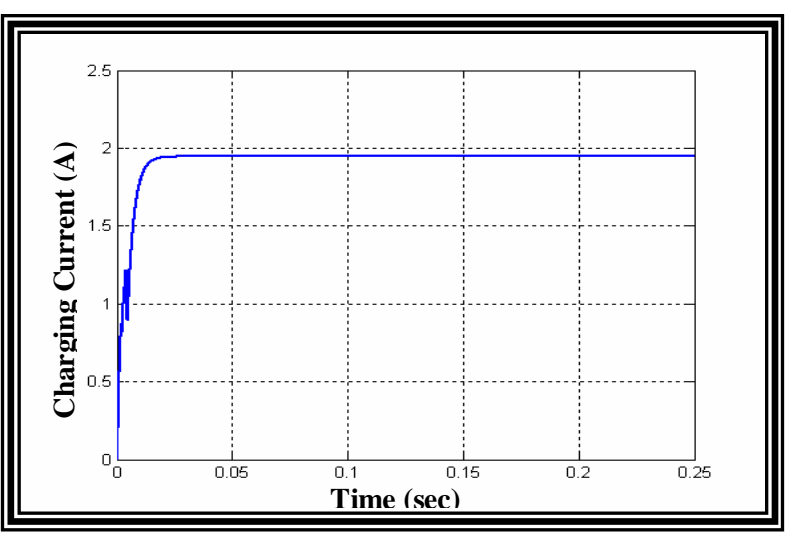

(b): charging current with perturbation and observation algorithm.

Figure (6): Computed charging current. a) without MPPT.

b) with $\mathrm{P} \& \mathrm{O}$ algorithm and c) with IncCond algorithm. 
It is noticed that the charging current is increase about (11\%) when using perturbation and observation algorithm and increased about (15\%) with incremental and conductance algorithm. The captured maximum power is approximately $(38 \mathrm{~W})$ in the first algorithm and it is $(42 \mathrm{~W})$ for second algorithm. The tracking efficiency was used to evaluate the tracking performance for MPPT algorithm, the tracking efficiency is defined as:

$$
\eta_{M P P T}=\frac{\int_{t_{1}}^{t_{2}} P_{\text {actual }}(t) \cdot d t}{\int_{t_{1}}^{t_{2}} P_{\max }(t) \cdot d t}
$$

Where $\mathbf{t} \mathbf{1}$ is the start- up time of the system and $\mathbf{t} \mathbf{2}$ is the close-down time of the system, $\mathrm{P}$ is the panel output power, and Pmax is the theoretical maximum panel power. The tracking efficiency for the two kinds of algorithm is above (80\%).

\section{Experimental Results}

Fig (7) shows the overall view of the maximum power point tracking system. The main sections are the solar cell, the microcontroller, the dc-dc converter (boost converter) and the load, which in this case is the charging battery.

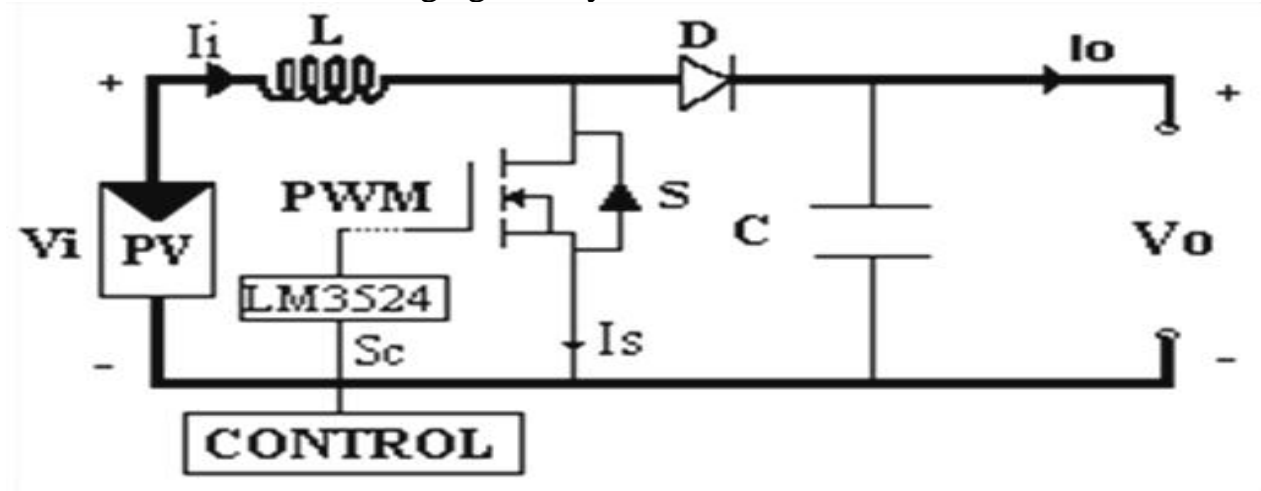

(a): Boost converter

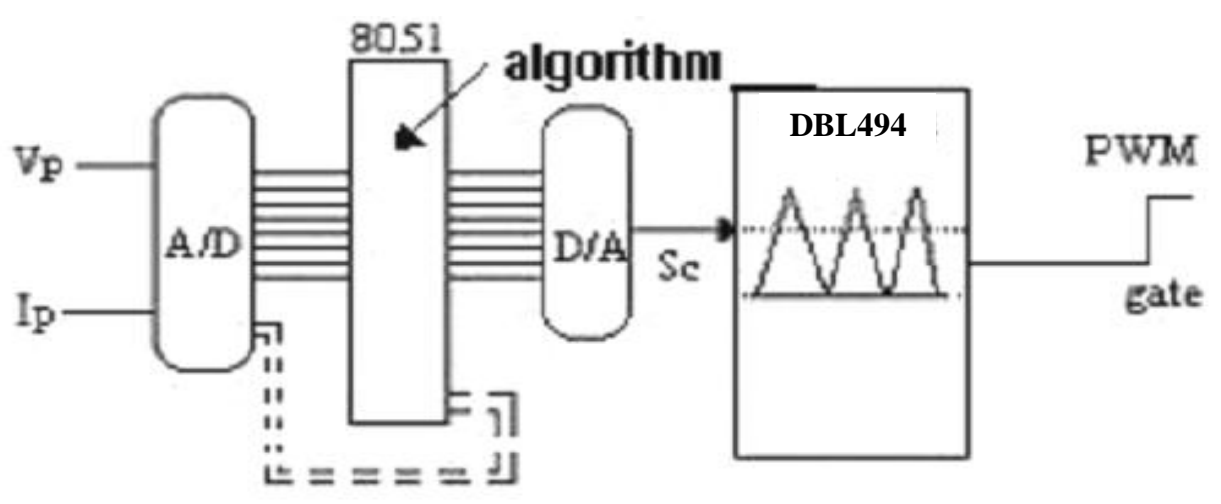

(b): control circuit diagram.

Figure (7): Maximum power point tracker. a) Boost converter, b) Control circuit diagram 


\section{Al-Rafidain Engineering $\quad$ Vol.17 $\quad$ No.6 $\quad$ Dec. 2009}

The dc-dc converter is placed between the solar panel and the load in order to draw the maximum power from the solar panel. The converter is an essential section as it operates the solar array at the maximum point while also providing a constant voltage to the battery. It is operated in boost mode, which step-up the output voltage. The regulation of the output voltage is achieved by varying the duty cycle of the switch (MOSFET). The PWM signal generated by 89C51 microcontroller is used to control the transistor switch operation (on \& off). The converter has all of the array energy flowing through it so component choice is important for maximum efficiency. The converter also carries out impedance matching so that the impedance of the source is equal to the impedance of the load to ensure maximum power transfer [9].

The microcontroller is also an imperative element of the system. It is responsible for implementing the maximum power point tracking algorithm, it takes continual measurements of the solar array output current and voltage and then continuously estimates what point the panel should be operating at for optimum power. It also controls the pulse width modulation with continuous switching of the dc-dc converter so that the output voltage can be set as desired. The DBL494 chip is used as a comparator to generate the PWM control signal, it has an internal saw tooth generator and comparator to compare the reference voltage that generate from microcontroller after executed the tracking algorithm to generate the PWM signal.

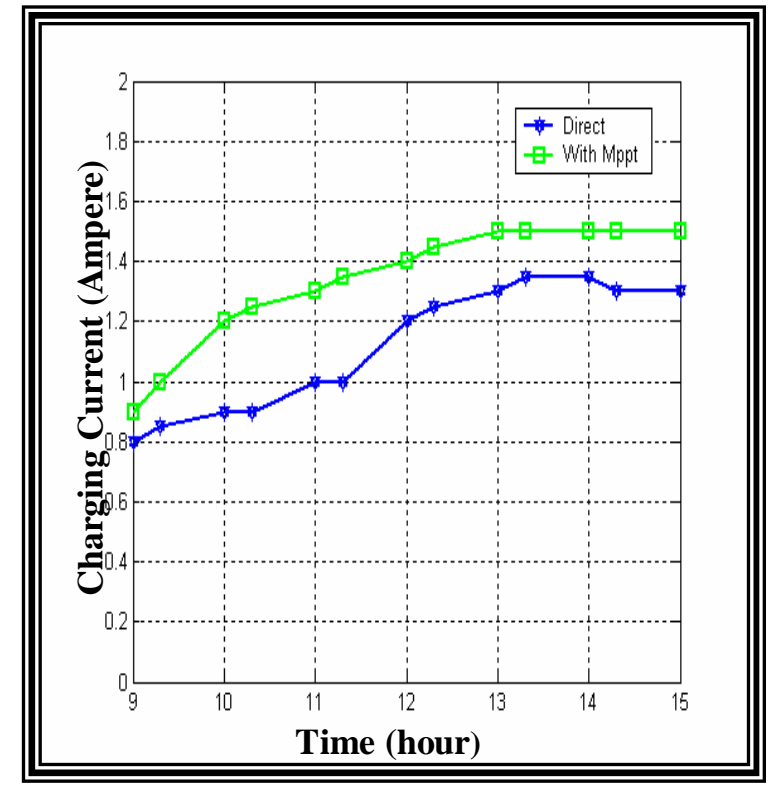

(a)

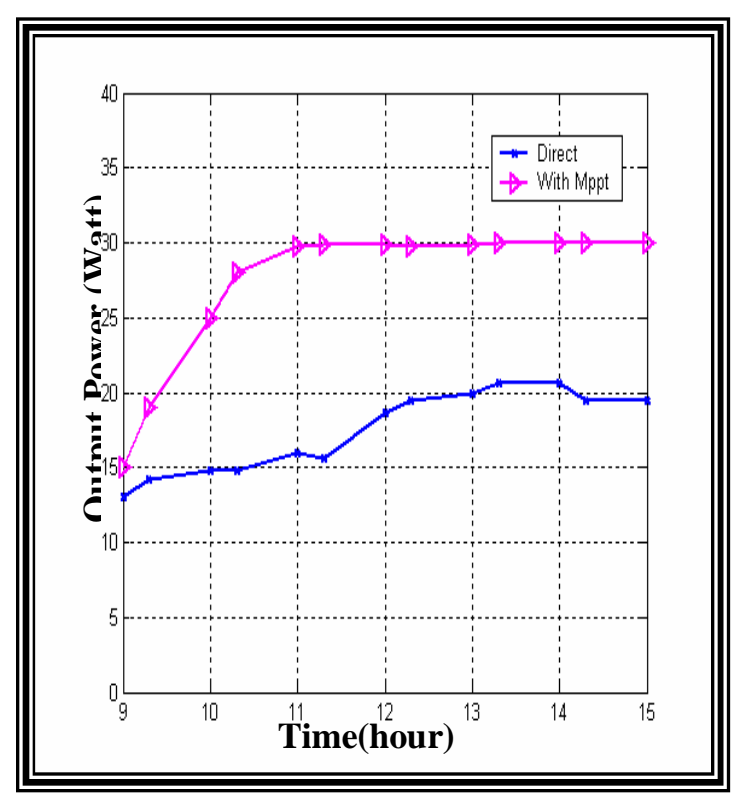

(b)

Figure (8): Measured a) charging current and

b) output power with and without using perturbation and observation algorithm.

Figure (8) shows the measured charging current and output power with and without using perturbation and observation algorithm, it can be noticed that the charging current increased to about (14\%) and the output power is increased to about $(10 \%)$ due to the increasing into output power exploited from solar panel. 
Mohamed : A High Efficiency Maximum Power Point Tracker for Photovoltaic ...

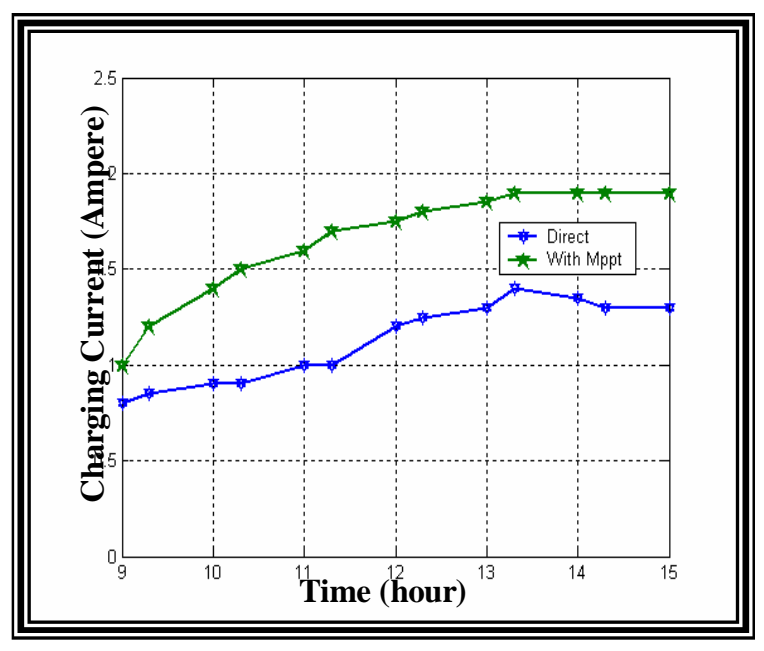

(a)

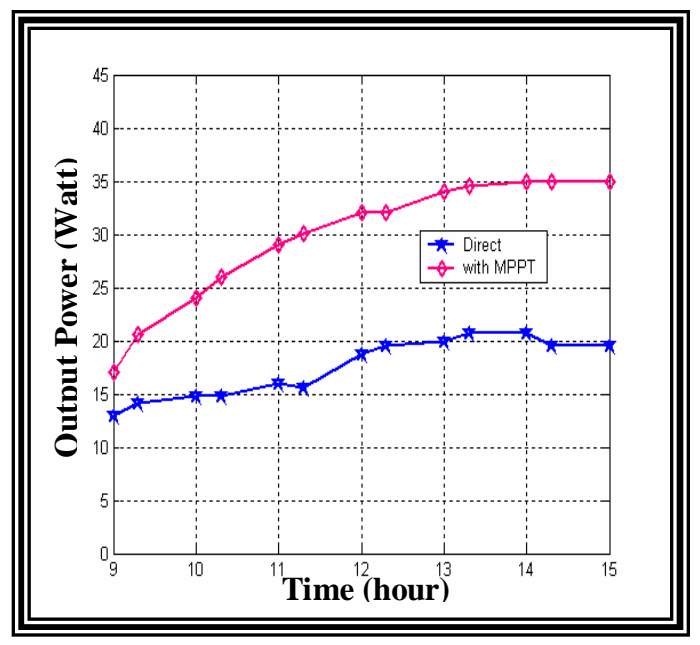

(b)

Figure (9): Measured a) charging current and

b) output power with and without using Incremental conductance algorithm.

Figure (9) shows the measured charging current and output power with and without using Incremental conductance algorithm; the charging current is increased to about (35\%) while the output power is increased to about (15\%).

The tracking efficiency of the first algorithm is about (80\%), and for the second algorithm is about $(95 \%)$, so that the second algorithm is more efficient from the first algorithm to track the maximum power point of the photovoltaic system, because the first algorithm is oscillate at the maximum power point and not centered on it.

\section{Conclusion}

The purpose of maximum power point tracking is to adjust the solar operating voltage close to the peak power point under changing atmospheric conditions. The main goal of this work is to increase the efficiency in comparison to systems without MPPT, and thus to reduce the size and the cost of the PV panel. It consists of a dc-dc boost converter controlled by a single chip microcontroller that executes a two tracking algorithms perturbation and observation and Incremental conductance. The use of a microcontroller allows easy system modification, if additional renewable energy sources (e.g., more PV array) are used. The method has an advantage of unnecessarily knowing the solar array characteristics, thus it can be applied to all types of solar modules. Another advantage is that the system eliminates the reference cell used in other systems. It noticed that the incremental conductance algorithm shows tracking efficiency better than the perturbation and observation algorithm because the last one is oscillate around the maximum power point and not centered on it. the experimental and simulation results are presented to show the performance validity of the designed MPPT. 


\section{Reference}

[1] M.Veerachary, T. Seniyu and K. Uezato., "Maximum Power Point Tracking Control of IDB Converter Supplied PV System”, IEE Proc. Electronic. Power Application, vol.148, No.6, pp.494-502, November 2001.

[2] Y. Hsiao and C. Chen., "Maximum Power Tracking for Photovoltaic Power System", IEEE, pp.1035-1040, 2002.

[3] S. Armstrong and W. Hurley, "Self- Regulating Maximum Power Point Tracking for Solar Energy Systems", Power Electronics Research Center, National University of Ireland, Galway,pp.604-609.

[4] A. Mohammad, H. Dehabonei and F. Ewald., "Theoretical and Experimental Analyses of Photovoltaic Systems with Voltage-and Current- Based Maximum Power Point Tracking”, IEEE Transactions on Energy Conversion, vol.17, No.4,pp.514-522, December 2002.

[5] D. Hohamand and M. Ropp., "Comparative Study of Maximum Power Point Tracking Algorithms using an Experimental, Programmable, Maximum Power Point Tracking Test Bed”, IEEE, pp.1699-1702,2000.

[6] R. Charles and J. Matthew., "A High- Efficiency Maximum Power Point Tracker for photovoltaic Arrays in a solar- Powered Race Vehicle", IEEE, pp.574-580, 1993. [7] X. Wang and M. Kazerani., "A Novel Maximum Power Point Tracking Method for Photovoltaic Grid- Connected Inverters”, IEEE, pp.2332-2337, 2003.

[8] C.Hua and C.Shen. "Comparative Study of Peak Power Tracking Techniques for Solar Nathan, M .Michelle and M.Huntery., "Maximum Power Point Tracker Development Project Storage System", IEEE Transactions on Power Electronic System, 1998. [9] D. Design Review", EE 461/CprE 481, No.13, December 1998. 